\title{
Artritis reumatoide como forma de presentación de un timoma
}

\author{
Rheumatoid arthritis presenting as a thymoma
}

\author{
Juan Antonio Velasco Franco, María Martín-Toledano, Marta Salas Cabañas, Pedro Reales Figueroa, Laura Fernandez \\ Espartero, Joaquín Castro, Adrián Ruiz, Mercedes Muñoz Pasadas, Nuria Reyes.
}

Servicio de Medicina Interna, Hospital General de Valdepeñas, Castilla la Mancha (SESCAM)

\section{Resumen}

El timo juega un importante papel en la maduración de los linfocitos T y en la tolerancia inmune, una alteración a dicho nivel podría desencadenar una reacción de linfocitos contra antígenos propios, dando lugar a reacciones autoinmunes.

Presentamos el caso de un paciente de 65 años diagnosticado hacía 4 años de artritis reumatoide seropositiva controlada con bajas dosis de corticoide que ingresó en el servicio de Medicina Interna por cuadro sincopal situacional (defecatorio) con recuperación espontánea. En las exploraciones complementarias destacaba la presencia en la radiografía de tórax de una masa mediastínica confirmada en TAC y con biopsia compatible con timoma.

Tras el hallazgo casual del timoma y 2 años después de la extirpación del mismo el paciente se encuentra asintomático sin tratamiento corticoideo en lo que respecta a artritis y con negativización en controles posteriores a la cirugía de factor reumatoide y anticuerpos anticitrulinados en descenso.

Palabras clave: timoma; artritis reumatoide; linfocitos; autoinmunidad

Keywords: Thymoma. Rheumatoid arthritis. Lymphocytes. Autoimmunity

\section{Caso clínico}

Paciente de 65 años con antecedentes personales de HTA, artritis reumatoide seropositiva, hepatitis B pasada y fumador (40 cig/día) hasta hacía 5 años cuyo tratamiento habitual era calcio/vitamina D3 (1500/400) (1-0-0) Imidapril $10 \mathrm{mg}$ (1-0-0), risedronato 35 semanal, prednisona $2.5 \mathrm{mg}$ (1-0-0) y omeprazol 20 (1-0-0).

Ingresó en el servicio de Medicina Interna por cuadro síncopal situacional (defecatorio) con recuperación espontánea y exploración sin datos reseñables. En las pruebas complementarias solicitadas llamaba la atención la presencia en la radiografía de torax de una masa mediastínica. En el resto de las pruebas de laboratorio destaca LDH 499 UI/L (200 - 400) Proteinograma normal con IgG $1700 \mathrm{mg} / \mathrm{dl}(700$ - 1600) Ferritina $480 \mathrm{ng} / \mathrm{ml}(22$ - 322) Leucocitos 11. 000/ul (4. 1 - 10. 0) Neutrófilos $52.7 \%$ (55. 0 - 65. 0) Eosinófilos $9.4 \%$ (0.5 - 4. 0) Hemoglobina $16.7 \mathrm{~g} / \mathrm{dl}(11.9$ - 16. 3) MCH 32.8 pg (26. 0 - 34. 0) VCM 94.8 fl (80. 0 - 100).

Se solicitó TAC torácico (Imagen 1) en el que se evidenciaba masa sólida y con realce homogéneo, de bordes bien definidos y ligeramente lobulados, situada en mediastino anterior-espacio prevascular, de $8 \times 7,5 \mathrm{~cm}$ junto con dos adenopatías prevasculares, adyacentes a la tumoración descrita, con diámetros transversos de 7 y $9 \mathrm{~mm}$ que sugerían timoma como primera posibilidad.

Se realizó punción- biopsia de la masa con anatomía patológica sugerente de timoma formado por nidos sólidos de células con citoplasma amplio, núcleos redondos y nucleolos prominente, sin atipias ni mitosis, entremezcladas con abundantes linfocitos CD3 positivos y en la periferia delimitado parcialmente por una cápsula. Existían además imágenes de invasión capsular y del tejido adiposo adyacente sin alcanzar los extremos de resección (Imagen 2). El inmunofenotipo finalmente resultó compatible con timoma predominantemente mixto o timoma $\mathrm{AB}$.

Previamente al diagnóstico de timoma el paciente era seguido desde hacía 4 años en la consulta de Reumatología por episodios de tumefacción de metacarpo-falángica y carpos de ambas manos sin rigidez, fue diagnosticado de artritis reumatoide seropositiva que controlaba inicialmente con AINEs y posteriormente asociando dosis de prednisona de $15 \mathrm{mg}$ al día que fueron descendiendo progresivamente hasta mantenerse con dosis de $2.5 \mathrm{mg}$ al día sin artritis. Tras la extirpación del timoma el paciente fue seguido durante 2 años en la consulta de Medicina Interna y Reumatología con negativización del factor reumatoide y anticuerpos anticitrulinados en descenso (Tabla 1). Tras la retirada de corticoide presentó artritis durante el último año de seguimiento.

\section{Discusión}

El timoma es la causa más común de tumores del mediastino anterior (20\% de los tumores mediastínicos y $50 \%$ de los tumores de mediastino anterior). Es un órgano del sis-

Tabla 1. Evolución temporal de los niveles de anticuerpos

\begin{tabular}{|c|c|c|c|c|c|c|c|}
\hline Analítica: & $21 / 10 / 08$ & $30 / 08 / 11$ & $14 / 02 / 12$ & $\begin{array}{c}24 / 10 / 14 \\
\text { (Cirugia timoma) }\end{array}$ & $23 / 12 / 14$ & $16 / 02 / 15$ & $27 / 05 / 15$ \\
\hline FR & $25 \mathrm{UI} / \mathrm{ml}$ & $31.6 \mathrm{UI} / \mathrm{ml}$ & & & $<10 \mathrm{Ul} / \mathrm{ml}$ & $<10 \mathrm{Ul} / \mathrm{ml}$ & $<10 \mathrm{Ul} / \mathrm{ml}$ \\
\hline Anti-CCP & & & $431 \mathrm{Ul} / \mathrm{ml}$ & & $47 \mathrm{Ul} / \mathrm{ml}$ & $23 \mathrm{Ul} / \mathrm{ml}$ & $25 \mathrm{Ul} / \mathrm{ml}$ \\
\hline ANAs & & & $\begin{array}{c}1 / 1601 / 320 \\
\text { Patrón mixto }\end{array}$ & & & Negativos \\
\hline Ac-anticolisnesterásicos & & & $<0.1 \mathrm{mmol} / \mathrm{l}$ & & & \\
\hline
\end{tabular}


Figura 1. Masa sólida y con realce homogéneo, de bordes bien definidos y ligeramente lobulados, situada en mediastino anterior de 8x7. $5 \mathrm{cms}$ sugestiva de timoma

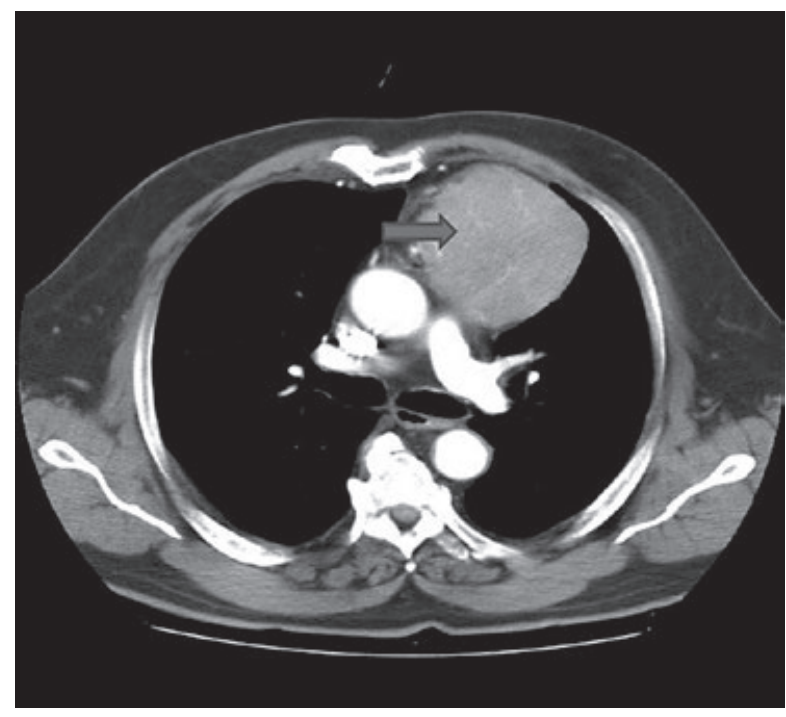

tema linfático cuyo desarrollo ocurre desde el nacimiento a la pubertad, alcanzando en esta etapa un tamaño de aproximadamente 40 gramos para posteriormente involucionar y pasar a un estado atrófico en edad avanzada. Su función consistiría en la maduración de linfocitos T (evolución de célula T inmadura a T helper (CD4) -citotóxicas (CD8) y migración a la circulación) junto con el desarrollo de tolerancia inmune (Linfocitos T reguladores-TREGS) ${ }^{1}$

El paciente que nos ocupa fue diagnosticado de artritis reumatoide seropositiva cuatro años antes y seguido posteriormente en la consulta de Reumatología. Teniendo en cuenta que el tiempo de evolución entre el inicio de síntomas y el diagnóstico de timoma suele ser prolongado y en la mayor parte de casos el diagnóstico es casual, es bastante probable la relación causal entre timoma y artritis reumatoide, hecho que refuerza la ausencia de clínica sugestiva de artritis y la practica negativización de anticuerpos tras la extirpación del timoma.

La presencia de timoma se asocia además de a fenómenos autoinmunes a segundas neoplasias e inmunodeficiencias. Hay escasos estudios que aclaren el porqué de esta asociación aunque probablemente se deba a una alteración en la subpoblación de células T (descenso del cociente CD4/CD8 y menor cuantía de ambas poblaciones), un desequilibrio en la síntesis y respuesta a las citoquinas y a una alteración de los linfocitos T TREGS, fundamentalmente de procedencia tímica y que juegan un importante papel en el control de la tolerancia inmune? ${ }^{2}$
Figura 2. Timoma formado por nidos sólidos de células de citoplasma amplio, núcleos redondos y núcleos prominentes, sin atipias ni mitosis, entremezcladas con abundantes linfocitos CD3 positivos. En la periferia esta parcialmente delimitado por una cápsula. Imágenes de invasión capsular y del tejido adiposo adyacente sin alcanzar los márgenes de resección.

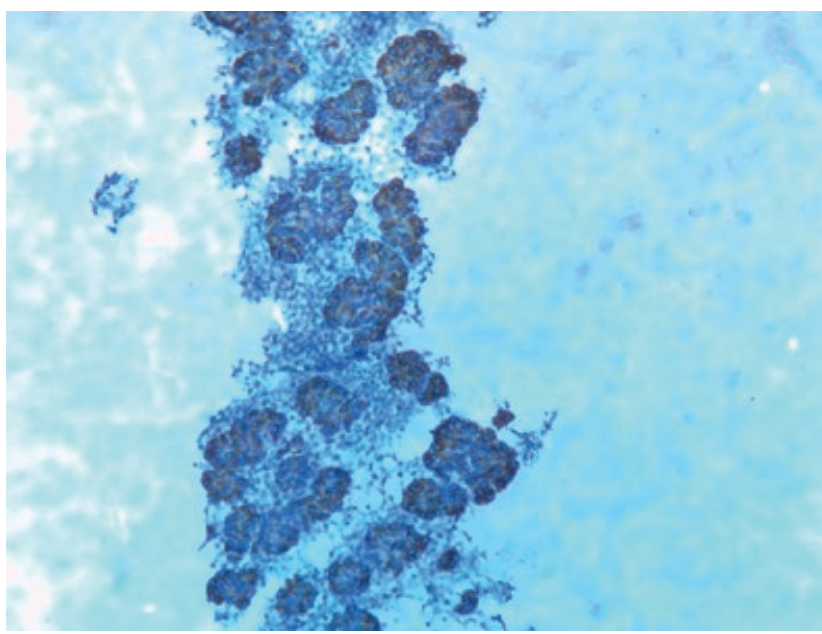

La forma más frecuente de presentación de un timoma suele ser como un incidentaloma o debida a fenómenos compresivos / inmunes². Se han publicado múltiples fenómenos autoinmunes en relación con timoma, fundamentalmente en relación con miastenia gravis, pero también polimiositis, lupus, artritis reumatoide, tiroiditis, Sjogren, hepatitis autoinmune, enfermedad celiaca, pénfigo....y en ocasiones solapándose unas a otras ${ }^{3}$ dejando entrever por tanto una relación inmunopatológica ${ }^{1}$

La diferenciación histopatológica (clasificación Who) parece tener relación con la asociación a autoinmunidad siendo el fenotipo B2 el más frecuentemente asociado². La asociación con artritis reumatoide es poco frecuente con tan solo 3 casos descritos en literatura, uno asociado a tiroiditis de Hashimoto ${ }^{4}$ y dos de ellos asociados a la toma de fármacos inmunosupresores y aparición de timoma en dicho contexto 5,6 .

\section{Bibliografía}

1. Fletcher AL, Calder A, Hince MN, Boyd RL, Chidgey AP. The contribution of thymic stromal abnormalities to autoimmune disease. Crit Rev Immunol. 2011;31(3):171187

2. Thongprayoon C, Tantrachoti P, Phatharacharukul P, Buranapraditkun S,Klaewsongkram J. Associated immunological disorders and cellular immune dysfunction in thymoma: a study of 87 cases from Thailand. Arch ImmunolTher Exp (Warsz) 2013;61:85-93.

3. Holbro A, Jauch A, Lardinois D et al (2012) High prevalence of infections and autoimmunity in patients with thymoma. Hum Immunol 73:287-290

4. Zou L, Xiong Z, Dun Y, Xiong Y A case of rheumatoid arthritis associated with Hashimoto's thyroiditis and thymoma Int J Rheum Dis. 2014 Oct 10.

5. Usui T, Nakao H, Ishikawa K, Nakamura K, Yamane T, Katayama S. Case of thymoma complicated with rheumatoid arthritis. Nihon Naika Gakkai Zasshi. 1999 Jun 10;88(6):1094-5

6. Colburn KK, Cao JD. Thymoma associated with rheumatoid arthritis in a patient taking methotrexate. J Rheumatol. 1986 Apr;13(2):437-9. 